\title{
Os dilemas do processo de mudança em uma organização pública: Uma análise das representações sociais sobre a prática de $P \& D$ multi e interdisciplinar
}

\author{
Mozar José de Brito ${ }^{1}$ \\ Mônica Carvalho Alves Cappelle ${ }^{2}$ \\ Valéria da G. Pereira Brito ${ }^{3}$ \\ Luciana Cramer ${ }^{4}$
}

Resumo: Este trabalho teve por objetivo investigar o processo de mudança na organização do trabalho de $\mathrm{P} \& \mathrm{D}$ em uma organização pública. Mais especificamente, este estudo de caso procura desvendar o conjunto de representações sociais construídas por pesquisadores e gestores em torno da institucionalização de uma nova forma de organização do trabalho de $\mathrm{P} \& \mathrm{D}$, cuja especificidade pressupõe a aplicação prática das noções de multi e interdisciplinaridade. A dinâmica cultural produzida em decorrência da introdução dessa mudança organizacional desencadeou a construção de diferentes representações sociais em torno da organização do trabalho em equipes multi e interdisciplinares. A interpretação dessas construções simbólicas, tomando como referência a cultura dominante institucionalizada ao longo da história da organização, ilustra que a implementação de um novo modelo de organização do trabalho não é um processo que ocorre de forma total, apenas pela modificação na forma de organização da produção científica. Mas, ao contrário, trata-se de um processo que envolve $o$ questionamento e a superação dos padrões culturais até então vigentes nesse espaço organizacional. Portanto, o reordenamento do universo simbólico, incluindo as representações sociais elaboradas pelos diferentes atores organizacionais.

\section{Introdução}

A organização do trabalho em equipes multi e interdisciplinares vem sendo cada vez mais adotada pelas organizações públicas de pesquisa, o que pode ser notado tanto pela observação da prática organizacional, quanto pelo contato com trabalhos teóricocientíficos que discutem a teoria das organizações. De fato, muitos autores têm enfatizado os benefícios do trabalho em equipe aplicado ao ambiente atual, que exige rapidez de respostas, flexibilidade, criatividade e constantes mudanças por parte das organizações e de seus membros.

Entretanto, muitas organizações não têm obtido os resultados esperados com a substituição da especialização e da monodisciplinaridade tradicionais. Da mesma forma, muitos empregados não estão satisfeitos com a alteração da modalidade de trabalho, ou até mesmo resistem à sua adoção, seja por não estarem devidamente preparados para a mudança, por suas especificidades culturais, comportamentais e sociais, ou por falhas na estratégia de implementação da prática de $\mathrm{P} \& \mathrm{D}$ multi e interdisciplinar por parte da

\footnotetext{
${ }^{1}$ Professor do PPGA/UFLA, Dr. em Administração/USP e Pesquisador da FAPEMIG e CNPQ. Endereço: CP.37, CEP 37.200.000, Lavras - MG

${ }^{2}$ Mestranda em Administração pelo PPGA, Bolsista da CAPES e Pesquisadora da FAPEMIG/UFLA

${ }^{3}$ Pro-Reitora de Graduação da UFLA, Mestre em Administração/UFMG e Pesquisadora FAPEMIG

${ }^{4}$ Psicóloga, Mestranda em Administração pelo PPGA, Bolsista da CNPq e Pesquisadora da FAPEMIG/UFLA
} 
organização, dentre outros fatores. Acredita-se que o caso que ora se apresenta seja adequado para ilustrar essa realidade.

Nesse sentido, com esta pesquisa, teve-se como objetivo analisar as representações sociais elaboradas por pesquisadores e gestores de uma organização pública de $\mathrm{P} \& \mathrm{D}$ em torno da implementação de uma nova organização do trabalho centrada na multi e interdisciplinaridade. Mais especificamente, buscou-se apresentar um resgate histórico da organização, particularizando suas peculiaridades culturais; descrever o processo de institucionalização de uma nova organização do processo de P\&D; e, finalmente, analisar as representações sociais elaboradas pelos pesquisadores em torno da introdução do trabalho em equipes multi e interdisciplinares, propriamente dito.

Para tanto, na primeira parte desse constructo apresentou-se uma elaboração teórica acerca do trabalho em equipes multi e interdisciplinares. Na segunda parte, resgatou-se a teoria das representações sociais que serviu de referência na análise das subjetividades socialmente construídas pelos pesquisadores e gestores em torno da prática de $\mathrm{P} \& \mathrm{D}$ multi e interdisciplinar. Posteriormente, apresenta-se a metodologia utilizada para a coleta e análise de dados, seguida da exposição dos resultados da pesquisa. Por último, são tecidas as considerações finais.

\section{A multi e interdisciplinaridade no espaço organizacional}

Acredita-se que as equipes de trabalho podem ganhar tempo ao eliminarem a necessidade de um processo de aprovação hierárquica para as tomadas de decisão, podendo também promover a melhoria dos processos por meio dos controles de qualidade (Galbraith et al., 1995). Além disso, a organização do trabalho em times enfatiza a busca pela inovação em produtos e processos e o aumento da satisfação dos consumidores, além de enriquecer a função do trabalhador ao enfocar o sucesso do grupo como um todo (Beckham, 1998). Nesse caso, o uso das equipes, ou times, é encarado com uma alternativa às abordagens tradicionais, baseadas na definição hierárquica dos cargos e na constante necessidade de supervisão, cada vez menos apreciadas pelos trabalhadores e pela sociedade (Lichtenstein et al., 1997).

Estes últimos autores valorizam a maior capacidade dos times de lidarem com elementos organizacionais mais complexos e acreditam que quanto maior for a diversidade promovida entre os membros da equipe, melhor será a sua performance. Nesse sentido, a diversidade da equipe visa a aumentar a capacidade de resolução de problemas, de produção de soluções mais criativas e de geração de decisões quantitativamente e qualitativamente melhores em relação a grupos mais homogêneos (Guzzo, 1986; Goffman \& Maier, 1961; Janis, 1982, citados por Lichtenstein et al., 1997). É o que se propõe mediante a formação de equipes de trabalho ou de pesquisa e desenvolvimento multi e interdisciplinares.

Os termos interdisciplinaridade e multidisciplinaridade, embora sejam usados comumente como sinônimos, apresentam diferenças conceituais. Para Jantsch, citado por Kendall e Mackintosh (1979), na pesquisa e desenvolvimento multidisciplinares não se percebe nem isolamento, nem cooperação, apenas um conjunto de disciplinas que estudam simultaneamente um mesmo problema, sem que as relações entre elas sejam definidas de modo explícito. Por sua vez, a pesquisa e desenvolvimento interdisciplinares requerem um esforço de coordenação em todos os níveis, caracterizado pela elaboração de um axioma comum ao conjunto das disciplinas 
conexas. Para Birbaum (1981), na pesquisa interdisciplinar, indivíduos representando diferentes áreas de especialização são reunidos para trabalhar num problema comum e seus esforços são integrados num todo coeso.

A multi e a interdisciplinaridade em $P \& D$ conduzem a múltiplas interações sociais na medida em que se reúnem especialistas de diferentes disciplinas, com diferentes processos de socialização e treinamento, linguagens e metodologias e esquemas conceituais próprios, podendo-se, a priori, deduzir a respeito das dificuldades de relacionamento de um grupo dessa natureza. Essa diversidade pode representar ao mesmo tempo conflitos de interesses, mas também se constitui numa fonte de mudança, aprendizagem de novos conhecimentos científicos. Devido a essa complexidade e às múltiplas interações que esse processo envolve, vários significados podem ser atribuídos pelos trabalhadores do conhecimento à organização do trabalho em torno de projetos multi e interdisciplinares (Brito, 2000).

A alteração do significado do trabalho para os trabalhadores em relação à implementação das equipes multi e interdisciplinares se dá, pois sua adoção pressupõe o rompimento com modelos organizacionais anteriores, em que cada trabalhador, ou equipe, atuava de forma monodisciplinar, exercendo funções específicas, sem possuir uma visão mais abrangente e sistêmica do processo produtivo. Nesse sentido, tanto os indivíduos como o ambiente organizacional devem se adaptar às novas formas de organização do trabalho introduzidas, para acompanhar as mudanças em relação ao sistema de produção, bem como aquelas referentes às novas formas de interação necessárias para o sucesso dessa inovação.

Dessa forma, para que uma equipe atinja resultados positivos, faz-se necessário um redesenho organizacional que se adapte às novas formas de organização do trabalho (Lipnack e Stamps, 1997). Nesse sentido, Beckham (1998) defende a mudança nos sistemas de motivação, avaliação, reconhecimento e recompensa da organização, que devem substituir o enfoque no esforço individual e monodisciplinar pela performance da equipe multi ou interdisciplinar. Além disso, deve-se desenvolver mecanismos capazes de integrar indivíduos, equipes e processos, como o uso de sistemas de informação e a fixação de missão, estratégias e valores condizentes com a nova orientação adotada (Galbraith et al., 1995). Consequientemente, esse autor acredita que o papel da gerência, ou liderança, também deva mudar. Ela passa a ser responsável por proporcionar um contexto adequado para o funcionamento eficiente das equipes multi e interdisciplinares, desenvolvendo e divulgando estratégias igualitariamente, em todos os níveis e para os diferentes membros, que facilitarão o esforço necessário para a implementação desses times; fornecendo canais eficientes de comunicação entre indivíduos e grupos; e, enfim, "orquestrando" o envolvimento entre as pessoas, mediante o fornecimento de orientação e ajuda ao desenvolvimento de cada um.

Outro fator que determina o sucesso desse tipo de equipe é o seu treinamento prévio, a fim de que seja capaz de romper com os pressupostos que orientam a monodisciplinaridade e possa desenvolver novas habilidades exigidas pelo trabalho multi e interdisciplinar. Para Beckham (1998), a organização deve promover sistemas sóciotécnicos de treinamento, enfocando o desenvolvimento de novas habilidades técnicas e sociais, com o intuito de facilitar e potencializar a capacidade de integração e de trabalho em grupo desses indivíduos. Nesse sentido, Lichtenstein et al. (1997) consideram a integração da equipe como um conceito multidimensional que trata tanto da maneira como os membros do time se relacionam e trabalham em conjunto, quanto da forma com que eles se interagem. 
Assim, uma equipe pode ser considerada integrada quando seus membros compreendem seu papel no grupo e se sentem confortáveis em partilhar seus pontos de vista nas discussões, estabelecimento de metas e tomadas de decisão conjuntos. Por outro lado, algumas equipes podem enfrentar dificuldades para atingirem seus objetivos quando seus membros revelarem a predominância de sentimentos como competitividade, conflito e hostilidade em relação a seus pares.

De fato, existem alguns elementos organizacionais que atuam como barreiras e resistências à formação das equipes, em especial, as multi e interdisciplinares. Beckham (1998) alega que o ensino e a prática das formas de gerenciamento tradicionais acabam promovendo a formação dessas barreiras. Assim, o próprio sistema administrativo tradicional institucionalizado, por constituir elementos que sofrem intensivamente os impactos da mudança, acaba se transformando em fontes de resistência à nova forma de trabalho. Além disso, a obsolescência técnica dos trabalhadores, entendida como a defasagem do estoque de conhecimento, habilidades e destrezas presentemente possuídos pelo indivíduo, em relação às necessidades de seu trabalho, para fazer face às demandas advindas da sociedade e ao estágio de avanço do respectivo campo científico, revela uma outra fonte de resistência ao trabalho em equipe (Brei, 1998a, 1998b).

Em detrimento das barreiras estruturais à implementação do trabalho em equipes multi e interdisciplinares, há outros elementos, de cunho individual, cultural ou social, que interferem na integração dos seus membros e prejudicam o funcionamento do grupo. Para Lipnack e Stamps (1997), existe um conflito entre as necessidades individuais e grupais, gerando uma tensão contínua nos indivíduos entre serem e precisarem ser diferentes dos outros, ao mesmo tempo tendo que se integrar a eles. Nesse sentido, as pessoas possuem diferentes habilidades, opiniões, interesses, personalidades, medos e motivações que podem levá-las a competir entre si pelo seu crescimento pessoal e profissional. Entretanto, para serem bem sucedidas na organização que adota o trabalho em equipe multi e interdisciplinar, devem cooperar com seus pares para que o time atinja suas metas e objetivos. Esse paradoxo a que estão expostos constantemente, muitas vezes, age como um mecanismo de pressão, expresso nas subjetividades desses indivíduos.

Para revelar esses elementos intrínsecos às subjetividades individuais construídos em meio a um contexto social, mostra-se adequada a utilização dos fundamentos da teoria das representações sociais, visto que seu conceito permite colocar em evidência, tomando como referência o contexto histórico-cultural, as características pessoais, os significados atribuídos à realidade, crenças, opiniões e atitudes acerca de um determinado fenômeno (Chamon, 2000).

\section{A teoria das representações sociais e a escolha metodológica}

$\mathrm{Na}$ análise organizacional, cada vez mais se tem buscado a transdisciplinaridade, visando a construção de quadros de referência que possam ampliar as possibilidades de interpretação da complexidade do espaço organizacional que reproduz, em parte, a dinâmica macro-social. Inspirado nessa idéia do diálogo teórico-metodológico, o presente trabalho tem uma proposta de análise que procurou estabelecer um movimento de complementariedade entre a administração e psicologia social na tentativa de apreender as representações sociais sobre a prática de P\&D multi e interdisciplinar em uma organização pública. 
Essa prática, que pressupõe a coexistência dos indivíduos em sociedade, é marcada pelo conflito entre o individual e o coletivo, considerado por Moscovici (1995) como realidade fundamental para a vida social. Esse conflito insurge e é promovido pelo confronto e tensão entre individualização e socialização que as normas formais elaboradas pelas instituições, existentes nas sociedades, conduzem a todo o tempo. Dessa forma, a construção de representações partilhadas permite uma certa regulação dessas tensões nos limites do suportável, pois não existe sujeito sem sistema, nem sistema sem sujeito, ou seja, vidas individuais, de acordo com Guareschi e Jovchelovitch (1995), só se formam e se constroem em relação a uma determinada realidade social. Desse modo, a teoria das representações sociais procura explicar a relação entre sujeito e o objeto-mundo, e, como, nessa relação, o sujeito é capaz de construir tanto o mundo como a si próprio.

Farr (1995) comenta que Moscovici, um dos fundadores da teoria das representações sociais, procura explicar uma categoria coletiva a um nível inferior, justificando que diante da complexidade das sociedades modernas poucas representações são verdadeiramente coletivas. Esse caráter mais localizado, específico e contextualizado das representações sociais e a possibilidade de rompimento da polarização entre individualismo e coletivismo que elas permitem, em consequiência, fazem com que estejam muito presentes nas teorias pós-modernas, adequando-se à investigação empírica das concepções leigas e fragmentadas da ciência. Assim, torna-se possível a articulação da vida coletiva de uma sociedade com os processos de constituição simbólica dos sujeitos sociais em sua tentativa de dar sentido ao mundo, entendê-lo e adaptar-se a ele (Jovchelovitch, 1995). Isso demonstra o caráter de resgate e revalorização da capacidade criativa e transformadora dos sujeitos que essa teoria permite.

Wagner (1995) sugere que a interpretação das representações sociais pode ser feita em dois níveis: o individual e o social/cultural. Para o autor, conforme o interesse de explicação do pesquisador, o conceito de representação também pode ser usado de duas formas distintas, avaliado em cada um desses níveis. Se os objetivos da pesquisa indicarem uma necessidade de identificação das características coletivas de uma representação social em um contexto determinado, deve-se procurar a existência das representações desse objeto social único nos diferentes subgrupos que o compõem, e nas elaborações diferenciadas dessas representações, de acordo com a relevância desse objeto para cada subgrupo.

O outro uso do conceito de representação se dá quando o interesse do investigador está focalizado nas características distribuídas das representações sociais entre os subgrupos de uma determinada unidade social. Nesse caso, busca-se a identificação das representações de indivíduos, como membros de grupos específicos, partindo-se para o nível de avaliação individual em uma amostra, geralmente homogênea, dentro de cada grupo. Em adição, o autor também destaca a relação macroredutiva existente entre a representação avaliada no nível individual e a avaliada no nível social: os membros dos grupos desenvolvem suas identidades e sua situação social quando em contato com o sistema social de entendimento, justificação e racionalização desenvolvido coletivamente. Portanto, torna-se possível transformar o fato social (macro) em um fenômeno mental individual, ou representação (micro), transformando atributos de uma coletividade em atributos compartilhados por indivíduos sociais.

Minayo (1995) reforça essa noção, ao afirmar que as representações sociais expressam a reprodução de uma percepção retida na lembrança ou do conteúdo do 
pensamento acerca da realidade, e, assim sendo, precisam ser entendidas com base no contexto em que se inserem e na sua funcionalidade para as interações sociais do cotidiano. Em outros termos, as representações sociais constituem uma forma de conhecimento socialmente elaborada e partilhada que, por esse motivo, possuem um objetivo prático e servem à construção de uma realidade ou verdade comum a um determinado grupo social. Para Barbieri (1991), esse caráter mutável, social e cultural se justifica pelo fato de elas serem produzidas, propagadas, reforçadas e negadas em um determinado meio, mediante a interação das pessoas que constituem esse meio.

Percebe-se, portanto, o papel determinante das representações, principalmente, em situações em que o indivíduo possui uma certa capacidade de interferir nas relações de poder e nas restrições impostas pela situação. Nesse sentido, Chamon (2000) defende a posição do pesquisador em relação a suas atividades de pesquisa como provedora de um certo grau de autonomia, por estas se inserirem em um espaço de ação relativamente aberto e permeável. Assim, mediante a utilização das representações sociais, poder-se-á acessar a visão de mundo de diferentes grupos de pesquisadores e demonstrar o conformismo, as contradições e os conflitos presentes na constituição dessas percepções. Isso é possível porque as representações sociais se manifestam em palavras, sentimentos e condutas, posteriormente institucionalizados e, por esse motivo, podem e devem ser analisadas mediante o estudo das estruturas e dos comportamentos sociais, cuja compreensão ocorre por meio da interpretação linguagem articulada pelos discursos socialmente construídos.

Para compreender as representações elaboradas pelos pesquisadores em torno do trabalho de P\&D multi e interdisciplinar adotou-se o método do estudo de caso (Trivinos, 1992; Yin, 1989; Laville e Dione, 1999; Vergara, 1998; Leenders e Erskine, 1989; Gil, 1996). Nessa reconstrução analítica procurou-se resgatar, numa perspectiva histórica, alguns traços da cultura organizacional e alguns elementos do modelo de gestão de $P \& D$ que ampliassem o potencial de análise das representações socialmente construídas em torno do processo de trabalho em equipe multi e interdisciplinar (Fleury, 1986; Demo, 1985).

$\mathrm{Na}$ pesquisa de campo empregaram-se diversas técnicas, incluindo a análise documental que possibilitou o acesso ao material de arquivo acerca da história da organização, principalmente no que dissesse respeito a políticas de \&stão de $\mathrm{P} \& \mathrm{D}$, mais especificamente à organização do trabalho (Vergara, 1998; Trivinos, 1992; Covaleski et al., 1998). Posteriormente à análise documental, foram realizadas 72 entrevistas semiestruturadas, sendo $10 \mathrm{com}$ gestores e $62 \mathrm{com}$ pesquisadores lotados na organização denominada, para os fins desse trabalho, de "Organização Delta". A técnica de entrevista foi escolhida por ser considerada menos rígida, no sentido de conservar uma certa padronização das perguntas, sem impor opções de respostas; e, também, menos constrangedora, por permitir aos entrevistados (pesquisadores e gestores) expressarem alguns elementos constitutivos das representações construídas em torno do trabalho multi e interdisciplinar (Vergara, 1998; Laville e Dionne, 1999). Após as entrevistas, realizou-se uma análise dos discursos, considerada um método adequado à identificação das representações sociais (Spink, 1995; Jovchelovitch, 1995).

Para apreender as referidas representações, procurou-se articular o modo de organização textual, formado pelo espaço do sujeito, o momento de enunciação e a história do interlocutor (Sitya, 1995; Orlandi, 1996). Da mesma forma, buscou-se orientação na análise de discursos adotada por Peterson e Albrecht (1999), que utilizam três estratégias analíticas de desconstrução, descritas por Martin (1990): atentar para 
rupturas, contradições ou momentos em que o discurso do entrevistado perde o sentido; interpretar as metáforas identificadas como uma fonte rica de múltiplos significados; e examinar os silêncios e pausas, ou o que ficou subentendido. Essa metodologia facilitou a explicitação das premissas ideológicas disfarçadas no discurso e permitiu revelar as representações sociais dos pesquisadores e gestores em relação à adoção do trabalho em equipe multi e interdisciplinares.

\section{História da organização estudada e a lógica do trabalho monodisciplinar}

Ao ser fundada, para cumprir a sua missão de gerar conhecimento científico e tecnológico voltado para o processo de modernização da agricultura brasileira, a empresa de P\&D estudada "desenhou" um modelo organizacional que promoveu uma profunda alteração na gestão da produção científica e tecnológica voltada para o setor agropecuário. Essa concepção de gestão da pesquisa institucionalizou uma forma de organização do processo de produção científica e tecnológica cujas principais características eram a divisão do trabalho de pesquisa com outras instituições nacionais e a separação entre os processos de inovação, adaptação e de transferências de tecnologias. A divisão do trabalho previa também que as ações da pesquisa nacional deveriam orientar-se, fundamentalmente, pela lógica da pesquisa aplicada, ficando a cargo das universidades as pesquisas básicas.

Esse modelo de planejamento e gestão vigorou até dezembro de 1979, quando a organização pesquisada instituiu um novo conjunto de normas e procedimentos que deveriam orientar a pesquisa pública aplicada ao setor agropecuário. $\mathrm{O}$ novo conjunto de regras e procedimentos instituído, ao ser introduzido, visava, em tese, a promover a descentralização do processo de gestão dos programas e projetos de pesquisa. O novo modelo pressupunha também que a geração do conhecimento científico e tecnológico deveria "iniciar no produtor rural e nele terminar".

O modelo introduzido mostrou-se voltado para a racionalização do processo administrativo da pesquisa, eliminando a figura dos planos indicativos, dos programas estaduais e regionais. Em síntese, ele tinha como objetivo organizar e concentrar as ações dos centros em programas de pesquisa de alcance nacional, por produto (soja, hortaliças, leite, milho e sorgo) ou por recursos. Por se tratar de um modelo que promovia a especialização da pesquisa, era baseado, principalmente, na organização do trabalho monodisciplinar.

Esse modelo de gestão vigorou até o início da década de 1990, quando a "organização delta", apoiada nas técnicas de planejamento estratégico, iniciou um processo de mudança organizacional com o propósito de: realinhar as suas ações de pesquisa no sentido de aumentar a sua interação com a sociedade, especialmente com o setor privado; fortalecer o intercâmbio com a comunidade científica nacional $\mathrm{e}$ internacional; intensificar o processo de transferência de tecnologias por meio da promoção de negócios tecnológicos; promover um ajuste na política de recursos humanos; promover a descentralização administrativa e a modernização da infraestrutura de pesquisa; incentivar a excelência empresarial e manter um compromisso com a qualidade; dar prioridade à pesquisa aplicada em produtos e problemas estratégicos de expressão regional e nacional e ampliar as fontes de financiamentos e de receitas próprias. A estratégia adotada para implementar esse processo de mudança deveria também privilegiar a visão sistêmica, a multi e a interdisciplinaridade como fundamentos de pesquisa. Em síntese, a organização redefiniu o seu modelo de gestão 
de P\&D com o propósito de aumentar a sua eficiência e eficácia, de modo a ampliar a sua legitimidade social e, conseqüentemente, garantir sua sustentabilidade num contexto institucional (ambiente técnico e institucional) marcado por transformações políticas, econômicas, sociais e culturais. A análise desse processo de mudança é enriquecida pela reconstituição da história da organização, contada por seus membros.

A fundação dessa organização de pesquisa se deu num momento histórico em que o aparelho do Estado passava por uma reforma administrativa que pretendia introduzir uma racionalidade instrumental na administração pública capaz de romper com o patrimonialismo e o personalismo que permeavam as práticas de gestão nessas organizações. Para tanto, instalava-se a tecnoburocracia que pretendia impor uma lógica de gestão menos política e mais racional e qualificada, centrada na aplicação dos princípios da administração científica (planejamento, especialização, divisão do trabalho, formalização, monodisciplinaridade) nos moldes do formato empresarial vigente naquele momento histórico.

É importante mencionar que, mesmo sendo criada no período militar, a organização investigada sempre teve sua alta e média administrações constituídas por pesquisadores de carreira. Mas esse fato não impediu que essa organização de pesquisa passasse por uma espécie de isomorfismo interinstitucional (Rodrigues, 1997), cujas principais características foram a reprodução de alguns valores presentes na cultura militar (hierarquia rígida, meritocracia, valorização da racionalidade técnica) e a internalização da ideologia nacional-desenvolvimentista que permeava as ações de reforma do Estado e o processo de criação das empresas estatais.

Um outro desafio enfrentado por essa organização no momento de sua inserção histórica foi a falta de profissionais qualificados para compor o seu quadro de pessoal (Vargas, 1997a). Assim, foi necessário que ela adotasse uma política de recursos humanos centrada na capacitação dos seus pesquisadores e, como parte desta política, procurou-se contratar jovens talentosos na porta das universidades e das tradicionais escolas de ciências agrárias brasileiras, a fim de se eliminarem os vícios da administração pública anterior.

Na década de 1970, algumas universidades estrangeiras e praticamente todas as universidades brasileiras, em especial as tradicionais escolas de ciências agrárias, foram responsáveis pela disseminação de uma lógica de pesquisa agrícola que ficou amplamente conhecida como paradigma produtivista. Este paradigma tecnológico - $a$ revolução verde - no sentido colocado por Beus e Dunlap (1990), tem como fundamento epistemológico a racionalidade positivista (que valoriza a experimentação, a relação de causa e efeito e o reducionismo), dominação da natureza (exploração intensiva dos recursos naturais visando obter ganhos de produtividade), monodisciplinaridade e a especialização.

A análise de alguns depoimentos colhidos pelo presente trabalho sugere que, ao serem socializados por estas instituições, os pesquisadores apreenderam os valores da lógica produtivista e internalizaram os valores e crenças acadêmicos positivistas que reinavam e ainda reinam nas ciências agrárias. Em síntese, esses pesquisadores passaram por trajetórias culturais e educacionais semelhantes e compartilharam valores e normas de conduta orientados por pressupostos positivistas, como a monodisciplinaridade. Esse fato está expresso no seguinte depoimento: 
"A organização delta, ao enviar seus técnicos para os programas de pós-graduação, sofreu uma grande influência da visão universitária. Isto era estratégico e fazia parte da política de recursos humanos daquela época, pois no Brasil os programas de pósgraduação em ciências agrárias estavam iniciando e o mercado não oferecia profissionais com o perfil que a reorganização da pesquisa exigia naquele momento. Entretanto, a passagem do nosso pessoal pelas universidades, posso lhe afirmar, exerceu uma forte influência no nosso modelo de produção científica (...) O modelo de gestão da produção científica e tecnológica era marcado pela visão produtivista apreendida na universidade que, de certa forma, estava coerente com o modelo de agricultura que se pretendia fazer. Por outro lado, esse modelo de gestão acabou não acompanhando as transformações da sociedade, mais especificamente as demandas que emergiram no início da década de 90(...)” (Pesquisador e gestor de P\&D)

Um outro desdobramento dessa política forçada de contratação foi um sentimento de lealdade, orgulho, gratidão e comprometimento dos pesquisadores que viam nessa organização, que goza de alta credibilidade, aceitação e reconhecimento da comunidade científica nacional e internacional, a empresa que lhes deu a primeira oportunidade de emprego em uma área considerada nobre e que promove o progresso da sociedade. Assim, de certa forma, a organização teve a oportunidade de socializar seus pesquisadores conforme seus valores e crenças (Berger e Luckmann, 1996; Chao, 1988; Chatman, 1991 e Schein, 1988).

Esse comprometimento e orgulho desencadearam a criação do mito da competência técnica superior. Esse mito, ao permear a vida cotidiana da organização, passou a influenciar as práticas de gestão, estabelecendo prioridades e até mesmo determinando escolhas. O principal significado a ele atribuído é o da superioridade dessa organização em relação a outras instituições públicas de pesquisa e até mesmo uma certa arrogância organizacional e individual que contribuiu para a reprodução e adesão da lógica monodisciplinar. Esse sentimento de superioridade também contribuiu para que a organização mantivesse um certo distanciamento da sociedade e determinou a emergência de padrões de comportamento marcados pelo corporativismo, que encontraram na estabilidade e na garantia de emprego e no próprio plano de cargos e salários, que não permitia que os seus empregados fossem transferidos de um centro de pesquisa para o outro, um forte apoio.

“(...) éramos um grupo de pessoas competentes, todos com mestrado e doutorado nas melhores universidades do mundo. Éramos um grupo coeso, profundamente identificado com a pesquisa. No início nós trabalhávamos por amor à camisa, uma espécie de trabalho que tinha muito da devoção, do espiritual, do idealismo, da solidariedade, da camaradagem." (Relato de entrevista - pesquisador)

No plano individual, parece que o mito da competência também foi responsável pela criação de alguns "deuses da pesquisa", isto é, de pesquisadores que foram capazes de traduzir a sua competência técnica e especialização em capital simbólico'. A detenção desse capital simbólico se traduz também em maiores garantias de espaços políticos, no sentido de influenciar o estabelecimento de prioridades de pesquisa.

\footnotetext{
1 A noção de capital simbólico (que pode ser traduzido em reconhecimento, inserção, credibilidade, filiação institucional, controle de relações sociais dentro da comunidade científica) é um conceito relevante na compreensão dos posicionamentos políticos e valores dos que orientam as práticas de pesquisa e tem sido utilizado para classificar os pesquisadores numa espécie de hierarquia no seio das comunidades científicas (Guimarães, 1994:p.13)
} 
“(...) os pesquisadores daqui se julgam muito auto-suficientes, conhecedores de forma profunda das suas áreas de conhecimento, essa crença levou a uma certa acomodação (...) Este julgamento levou muitos pesquisadores a influenciarem fortemente os destinos da pesquisa. A crença na superioridade em termos de competência leva alguns pesquisadores a exercerem um forte controle daquilo que é pesquisado em muitos centros de pesquisa da organização delta." (Relato de Entrevista - pesquisador e gestor)

Além disso, a construção de uma configuração organizacional permeada por redes de poder em torno de áreas de conhecimento fez com que os pesquisadores passassem a gozar de ampla autonomia sobre os destinos da pesquisa. Dessa forma, os principais cargos da hierarquia eram por eles ocupados, levando a cultura organizacional a inibir a formação e a emergência de lideranças vocacionadas para área de gestão de ciência e tecnologia, especialmente para lidar com as ações humanas.

"A cultura da organização Delta sempre foi altamente concentradora de poder, acrescentando a isso um culto muito grande à figura de seu presidente, que tinha poder para indicar chefes e pessoas para os cargos estratégicos. Esse processo contribuiu para que se cometessem erros nas indicações e inibiu o surgimento de verdadeiros líderes e administradores de pesquisa e desenvolvimento (...)” (Relato de entrevista - ex-presidente)

Outro aspecto que contribuiu para a formação desse padrão cultural foi a adoção de uma política de capacitação centrada mais nas orientações dos próprios pesquisadores do que nas prioridades estabelecidas pela organização.

"A linha de treinamento em massa adotada no início da organização Delta criou uma espécie de trem da alegria. Os pesquisadores se afastavam de suas atividades para cursar mestrado e doutorado sem muito critério para a sua saída. Não existia muito controle sobre isso, embora levasse em consideração as prioridades da organização Delta, mas isso não eliminava a influência das pessoas. Teve casos de pesquisadores que desenvolveram seus trabalhos em áreas que não tinham nada a ver com as prioridades do centro em que ele trabalhava. Nessa política, sem dúvida, o que prevaleceu, muitas vezes foram os interesses dos pesquisadores(...)" (Relato de entrevista - pesquisador e gestor)

Como foi possível evidenciar, a história da organização, contada pelos seus membros, revelou uma cultura organizacional caracterizada pelo corporativismo existente na organização, pela lógica da orientação da pesquisas "por oferta" e pela baixa interatividade com outras organizações congêneres e com a iniciativa privada. A análise dos elementos culturais dessa organização desvendou também características de um tipo de organização do trabalho altamente especializado que valorizava $o$ individualismo e utilizava métodos de pesquisa que favoreceram a institucionalização da monodisciplinaridade.

Entretanto, pode-se perceber que os objetivos iniciais da organização entraram em choque com esses traços culturais, dando origem a uma espécie de "crise de identidade", que levou a diretoria executiva da organização a questionar o papel social que ela estava desempenhando. Essa "crise de identidade", associada a um conjunto de transformações que estão ocorrendo no ambiente técnico e institucional, estimulou a alta administração a deflagrar um processo de mudança na tentativa de ampliar a 
legitimidade social e, conseqüentemente, a sustentabilidade da organização Delta de P\&D.

\section{Pressupostos do novo modelo de gestão de P\&D: A organização do trabalho multi e interdisciplinar}

A partir do início da década de 1980, o acirramento da crise das economias capitalistas levou ao questionamento não só das estratégias de intervenção do Estado, mas, principalmente, das ações das organizações públicas de pesquisa a ele vinculadas, fazendo emergir um novo modelo econômico (Ribeiro e Faucher, 1994; Ribeiro 1999). Para Souza, Araújo e Campos (1991) e Martins Filho (1996), esse modelo envolve as estratégias de internacionalização das organizações, o movimento de capitais e uma forte ênfase no desenvolvimento científico-tecnológico. Diante desse contexto, o Brasil formulou, então, uma nova política de desenvolvimento, a qual, no que se refere à capacitação tecnológica, procurou estimular as empresas nacionais.

Visto dessa forma, existe uma tendência de o Estado reduzir progressivamente a sua participação no financiamento das atividades de pesquisa e priorizar investimentos na formação de recursos humanos e infra-estrutura. Assim, o financiamento relativo ao custeio das pesquisas, nas empresas públicas de pesquisa, passa a depender de outras fontes de recursos. Em reação a esse movimento, essas organizações tendem a introduzir nas suas culturas a lógica da comercialização do conhecimento, (Webster e Etzkowitz, 1991 citados por Maculan e Zouain, 1997), o que implica a revisão de conceitos, a introdução de uma orientação para o mercado e de outros valores organizacionais que estejam alinhados com as normas institucionalizadas neste novo contexto, como a multi e a interdisciplinaridade.

Associado a essas mudanças nas políticas públicas de C\&T, tem-se o processo de reforma do aparelho do Estado, que propõe às organizações de pesquisa uma autonomia administrativa e financeira mais competitiva, eficiente e voltada para resultados e para o atendimento da sua clientela. Essa proposta passa a exercer uma espécie de pressão coercitiva sobre as organizações públicas de pesquisa, inclusive no que se refere ao controle dos resultados e à adoção de novas formas de organização do processo de trabalho (Trevor e Bijker, 1993).

Nesse contexto, a organização pública de pesquisa analisada redefiniu a sua missão, objetivos, organização do processo de trabalho, formas de inserção no ambiente técnico e institucional, critérios de avaliação de programas, projetos e resultados do trabalho. Nessa construção social, a organização procurou redefinir as formas de relacionamento entre ela e seu ambiente técnico e institucional, a natureza das práticas de pesquisa (regras de comportamento, propriedade e orientação de tempo e espaço), a natureza dos relacionamentos humanos (atributos necessários e significados da realidade e do trabalho), e modificar a natureza da natureza humana (formas de interação social) (Schein, 1984; 1992).

Assim, o novo modelo de gestão adotado pressupõe uma orientação para o mercado (pesquisa por demanda) e se norteia pelo princípio melhoria contínua de produtos, serviços e tecnologias, bem como pela busca da excelência e foco no cliente. A construção social dessa relação pluralista com o ambiente institucional requer a 
modificação da própria natureza das práticas da pesquisa, mediante o desenvolvimento de projetos de P\&D que sejam capazes de lidar com toda a complexidade presente nas cadeias agroindustriais e que estejam alinhados com a lógica institucional, que evoca valores como modernização, produtividade, competitividade, qualidade e desenvolvimento sustentável. A conjugação de esforços e de competências na busca dessas soluções tecnológicas requer uma visão sistêmica das cadeias agroindustriais e uma organização do trabalho centrada na cooperação multi e interdisciplinar.

A multi e a interdisciplinaridade, nesse caso, implicam a construção de relacionamentos orientados para o trabalho em grupo e, principalmente, a concretização de projetos em rede orientados pelo princípio da cooperação intraorganizacional, ou seja, a cooperação e integração entre os diferentes centros de pesquisa da própria organização (Lichtenstein et al., 1997).

Para lidar com a complexidade do ambiente (técnico e institucional), o novo modelo de gestão pressupõe que os empregados da organização pesquisada (gestores, líderes e pesquisadores) tenham uma postura proativa em diferentes direções. Acreditase também que esse processo de desenvolvimento potencial humano dos pesquisadores deva envolver um programa de qualificação e de desenvolvimento das competências essenciais necessárias à produção do conhecimento científico e tecnológico de acordo com o novo modelo adotado (Beckham, 1998). Por isso, esses atributos devem ser reconhecidos, recompensados e premiados de forma seletiva e excludente. Faz-se necessário separar "o joio do trigo", "os produtivos dos improdutivos", os acomodados dos proativos", "os competentes dos incompetentes".

O novo modelo de organização e gestão de $\mathrm{P} \& \mathrm{D}$ dessa organização surgiu, então, como reflexo de valores e normas presentes no contexto institucional de referência (DiMaggio e Powell, 1983; Scott, 1992; Meyer e Rowan, 1992; Machado-daSilva e Fonseca, 1993; Machado-da-Silva, Fonseca e Fernandes, 1999). Assim, a organização estudada, ao adaptar-se às expectativas do seu contexto institucional, introduziu processos administrativos que dão forma ao seu novo modelo de gestão de P\&D (Beckham, 1998). Dentre eles, destaca-se o sistema de planejamento de projetos.

\subsection{O sistema de planejamento de projetos: entre disciplina rigorosa e a flexibilidade}

Por meio do acesso às representações sociais construídas pelos pesquisadores foi possível desvendar os significados atribuídos por eles ao novo processo administrativo adotado, bem como se permitiu a identificação de comportamentos de adesão e resistência à institucionalização do conjunto de valores que passou a orientar o novo modelo de gestão. $O$ processo de gestão analisado destinava-se a atividades de planejamento das atividades de $\mathrm{P} \& \mathrm{D}$ e, ao traduzir a visão organizacional, tinha uma função pedagógica relevante na institucionalização do novo modelo de organização do trabalho multi e interdisciplinar (Beckham, 1998). Esse sistema expressa a tentativa de redesenho organizacional para potencializar essa nova forma de organização do trabalho (Lipnack e Stamps, 1997). Portanto, atuou como fonte primária de referência para o pensamento e criação de representações sociais acerca da realidade organizacional socialmente construída em torno do processo de mudança em questão (Morgan, 1996).

Esse mecanismo burocrático, ao exercer sua função pedagógica, procura estabelecer os princípios e critérios a que os programas e projetos de pesquisa devem atender: a orientação para o mercado (pesquisa por demanda), raciocínio sistêmico, 
enfoque de P\&D, trabalho em equipe multi $\mathrm{e}$ interdisciplinar, lógica do desenvolvimento sustentado e a composição de arranjos inter-organizacionais ou parcerias estratégicas de cooperação científica e tecnológica. O sistema de planejamento prevê também a aplicação da gestão por processos e a adoção dos princípios da qualidade. Nesse contexto, os próprios projetos passam a ser instrumentos de gestão em torno dos quais se organiza o trabalho de pesquisa de tal forma a promover o exercício da multi e da interdisciplinaridade. Nesse caso, a organização do processo de trabalho de $\mathrm{P} \& \mathrm{D}$, pelo menos em tese, está configurada, de modo, a estimular a flexibilidade no uso em rede das competências de diversos especialistas.

Entretanto, é importante lembrar que, embora a alta administração defina estes critérios para a avaliação dos projetos, na prática não se tem um consenso em torno deles, exatamente por eles estarem sujeitos a diferentes interpretações por parte dos pesquisadores. A implementação de um modelo de organização do trabalho multi e interdisciplinar, em uma organização cuja cultura revela uma veneração ao mito da competência técnica superior, ao espírito corporativista e à orientação para a oferta de tecnologia, não é uma tarefa simples e nem se faz por meio do ajuste racional entre os meios e os fins desejados.

Entre os diferentes significados atribuídos pelos pesquisadores ao novo sistema de planejamento, observou-se a recorrência da representação social da organização burocrática, pouco ágil, carregada de um formalismo excessivo e de uma forte hierarquia, reduzindo a flexibilidade e não considerando a dinâmica do próprio projeto de pesquisa.

“(...) O sistema de planejamento apresenta uma rigidez extrema que reduz a flexibilidade do projeto.” (Relato de entrevista -Pesquisador)

A análise dessas representações sugere que este caráter burocrático e formalista assume uma conotação negativa que concorre para o desenvolvimento de uma série de resistências à implementação do novo modelo de gestão de P\&D.

“(...) Apesar do discurso de modernização e eficácia do sistema de planejamento, o que se viu foi uma ampliação da burocracia e um caos administrativo, causando um processo de competição selvagem entre indivíduos e a destruição do clima organizacional tão necessário a um ambiente que se propõe à geração de conhecimentos e tecnologia (...)” (Relato de entrevista pesquisador)

Esses relatos revelam alguns traços da burocracia descrita por Weber (1982, 1984), os quais não condizem com as características que potencializam a organização do trabalho em equipes multi e interdisciplinares (Beckham, 1998). A produção científica e tecnológica é mediada por comitês técnicos, escalonada hierarquicamente e regida por normas e procedimentos de um ethos racional-instrumental, restringindo a autonomia e a criatividade dos pesquisadores.

A alta administração da organização Delta, ao organizar o trabalho de P\&D em bases racionais, impôs uma disciplina orgânica, na medida em que instrumentalizou a orientação para resultados, determinando um rigoroso controle, a mensuração e normatização de cada ato relativo ao trabalho dos pesquisadores. Dessa forma, esse sistema de planejamento, em vez de contribuir com o nvo modelo de gestão adotado, provocou conflito entre a lógica de flexibilização e de cooperação, condizentes com a 
organização multi e interdisciplinar do trabalho, e a excessiva racionalização e controle sobre o processo de planejamento de projetos.

\subsection{A multi e interdisciplinaridade: movimentos de adesão e resistência}

A prática do trabalho em equipe na organização pesquisada aciona duas representações sociais. $\mathrm{Na}$ primeira, a multi e interdisciplinaridade assumem uma conotação positiva, em que estas abordagens são vistas como uma fonte de aprendizagem de novos referenciais teórico-metodológicos e como uma forma de organização do trabalho que permite o uso de competências e habilidades de maneira complementar, ampliando as possibilidades de explicação da complexidade dos fenômenos em foco pela pesquisa agropecuária.

"O trabalho em equipe permite que os talentos sejam usados de forma complementar na solução de problemas que geralmente apresentam uma alta complexidade.(...) Essa integração melhora o seu poder de explicação do fenômeno estudado (...)” (Relato de entrevista - pesquisador)

Além disso, há a visão de que o trabalho em equipe concorre para a aprendizagem de novos conceitos e de novas formas de abordar os problemas, bem como amplia as possibilidades de apresentar soluções tecnológicas de forma mais rápida. Essas significação são expressas da seguinte forma:

"O trabalho em equipe favorece a aprendizagem de novos conceitos e metodologias. (...) e isso aumenta a probabilidade de respostas mais rápidas para os problemas de pesquisa, pois há uma convergência de esforços na busca da solução(...). (Relato de entrevista - pesquisador)

“A pesquisa em grupo multidisciplinar(...) acaba expandindo as fronteiras do conhecimento do próprio pesquisador e do centro de pesquisa(...)" (Relato de entrevista - pesquisador)

A prática da multi e interdisciplinaridade aciona uma segunda representação social que revela os limites e as resistências a essa forma de organização do trabalho. Essa visão envolve ações oportunísticas orientadas pelo individualismo e pela competição entre os pares, dificuldades de relacionamento interpessoal, falta de comunicação e diálogo entre pesquisadores de diferentes áreas do conhecimento, falta de experiência com o trabalho em grupo e ausência de fundamentos filosóficos que sirvam de referencial comum para o trabalho em equipe. Além disso, reconhece-se a presença de limites teóricos metodológicos, de conflitos de interesses no momento de se apropriar dos resultados do trabalho em equipe e do paradoxo organizacional entre a orientação para o trabalho em equipe e a prática de avaliação baseada nos resultados do trabalho individual. Essa rede de significados revela-se da seguinte forma nas representações sociais dos pesquisadores:

"O trabalho de equipe é algo necessário e a empresa está cobrando isso, mas existe o individualismo e a competição entre os pesquisadores. Tem pesquisador que visa 
somente aos seus interesses de pesquisa e pessoais, como promoção e projeção na carreira. E o que é pior, é que a organização Delta estimula e premia as pessoas de forma individualizada. Se existe um estímulo para a competição, o trabalho em equipe multidisciplinar acaba sendo prejudicado(...)” (Relato de Entrevista - pesquisador)

A falta de diálogo e comunicação entre pesquisadores de diferentes áreas do conhecimento, características do método de gestão anterior, são um outro fator limitante para o trabalho em equipe. Na linguagem dos próprios gestores, estas dificuldades de consenso estão relacionadas à "existência de feudos organizacionais criados em torno de áreas de conhecimento" (relato de entrevista - pesquisador e gestor).

"O pessoal da área agronômica que trabalha com elementos biológicos e físicos tem uma enorme dificuldade de trabalhar com o pessoal da sócio-economia e vice-versa. Assim, uns estão preocupados com a quantificação e a maximização do potencial tecnológico e os outros estão preocupados com a relação custo benefício e os impactos econômicos-sociais da pesquisa. A união destas diferentes águas é muito difícil, mas é uma necessidade e uma determinação da empresa(...)” (Relato de Entrevista pesquisador)

“Um outro problema associado ao trabalho em equipe está na falta de comunicação. Muitas vezes a linguagem utilizada por alguns pesquisadores não é entendida pelos membros da equipe. Isso dificulta o entendimento e gera polêmica." (Relato de Entrevista - pesquisador)

As existências dessas subculturas, que empregam diferentes metodologias de pesquisa, utilizam formas de comunicação com jargões e linguagem próprios e orientam-se por diferentes valores, é percebida pelos gestores e pesquisadores entrevistados como um outro fator limitante ao trabalho multi e interdisciplinar, pois cada grupo imprime esforços políticos no sentido de sustentar suas posições e interesses (Lichtenstein et al., 1997). Nesse contexto, emergem também as dificuldades de comunicação, associadas ao emprego de diferentes formas de linguagem, induzindo ao conflito (Galbraith et al., 1995). Além disso, percebe-se, independentemente da área de conhecimento, a ausência de uma visão sistêmica que, aliada à especialização e à formação monodisciplinar, também dificulta a interação social entre os pesquisadores.

“(...) existe uma tendência de alguns pesquisadores valorizarem a sua área de pesquisa. (...) Essa visão acaba dificultando a integração da equipe e o exercício da interdisciplinaridade. Isto decorre da falta de visão sistêmica elou da dificuldade do pesquisador em perceber o problema de forma sistêmica (...)” (Relato de Entrevista pesquisador)

O esforço analítico empreendido por este trabalho demonstra que, além dos conflitos teórico-metodológicos presentes, emergem outros relacionados às ações oportunísticas de muitos pesquisadores no momento de decidir a forma de apropriação dos resultados do trabalho em equipe, o que pode ser relacionado à orientação individualista de alguns deles.

"A grande dificuldade de promover a pesquisa multi e interdisciplinar tem sua origem no individualismo que conduz a ações oportunísticas no momento de se concretizar a apropriação dos resultados. Sempre existe muita esperteza, tem líder de projeto e 
pesquisador querendo que os nomes deles estejam no artigo como primeiro autor, são tarefas que não são executadas pelos pesquisadores, dificuldades de comunicação entre as pessoas. Isso tudo gera desconfiança e então vem a falta de compromisso e o trabalho em equipe acaba perdendo o fôlego (...)" (Relato de Entrevista - pesquisador)

A regulação dos conflitos que emergem entre os pares e entre as equipes, sejam eles decorrentes das diferenças culturais ou da divergência de interesses, é tratada pelos gestores da organização como algo negativo e disfuncional que, em circunstâncias mais favoráveis, desapareceria (Morgan, 1996).

"essas divergências são da natureza humana; o pessoal não foi preparado para trabalhar em equipe; a visão é muito técnica, isso está na formação; poucos pesquisadores são capazes de observar o fim da linha; os pesquisadores se preocupam somente com a pesquisa em si mesma, eles são alienados" (Extratos de relatos de entrevistas com gestores).

Por meio da análise das representações sociais de grande parte dos pesquisadores, esses conflitos emergem porque não existe uma base filosófica e gerencial que sirva de referencial comum para a pesquisa multi e interdisciplinar (Beckham, 1998). Esse significado assume uma conotação paradoxal (Lipnack e Stamps, 1997), como sugere um gestor:

"Existem dois paradoxos no sistema de planejamento, o que, do ponto de vista do pesquisador, é muito difícil de se entender. Primeiro, que o sistema de avaliação está atrelado ao trabalho individual e o sistema de planejamento prega o trabalho em equipe(...) O segundo paradoxo diz respeito à falta de uma filosofia de pesquisa que nos oriente a trabalhar em grupo." (Relato de Entrevista - pesquisador e gestor)

A obsolescência do conhecimento técnico (Brei, 1998b), cuja origem está na evolução do conhecimento e na emergência de novas ondas tecnológicas, aciona representações sociais que revelam restrição ao trabalho em equipe. Essas representações expressam um sentido de frustração e medo de não ser capaz de atender aos anseios da clientela e de cumprir os objetivos organizacionais, medo de errar, tristeza e redução da auto-estima. Emergiram também sentimentos de constrangimento e medo diante dos pares (membros da equipe de trabalho, e principalmente, diante de técnicos estrangeiros e de outras organizações de pesquisa). Numa outra categoria de representações sociais, a obsolescência técnica é vista como algo desafiante para um grupo, mas que pode, ao mesmo tempo, gerar desconforto, frustração profissional e trazer dificuldade para a realização do trabalho em equipe.

"O trabalho multi e interdisciplinar é difícil, pois tem alguns pesquisadores mais antigos que estão com o conhecimento teórico e metodológico obsoleto, defasado e ficam com medo de se exporem junto aos membros da equipe. (...) Isto acontece porque tem muito pesquisador que acha que porque é doutor não precisa estudar mais (...)" (Relato de Entrevista - Pesquisador)

Associado ao processo de obsolescência do conhecimento tem-se a defasagem metodológica, também encarada como um entrave para a concretização do trabalho multi e interdisciplinar. Os pesquisadores da organização pesquisada, desde a sua 
criação, trabalharam com a metodologia experimental, que, segundo os entrevistados, é muito limitada. Para esses pesquisadores, existe uma forte tendência de a pesquisa agropecuária "deslocar-se do mundo experimental (traduzido pelo ambiente físico) para o ambiente de simulação e de outras técnicas laboratoriais mais avançadas" (Relato de entrevista - Pesquisador e Gestor) e que a maioria dos pesquisadores está com o conhecimento defasado para atuar nesses ambientes de elevada complexidade metodológica.

“(...) existe uma predominância muito grande da metodologia experimental, aquela que te faz racionar de forma fechada e parcelada. Esse tipo de metodologia que é ensinada nas universidades limita a compreensão de todo o sistema. Não sou contra a experimentação, mas acho que, por ser limitada, essa metodologia dificulta a prática da pesquisa multi e interdisciplinar, pois ela não abre espaço para que outros pesquisadores dêem a sua contribuição(...) Acho que temos que evoluir muito em termos metodológicos(...)" (Relato de Entrevista - Pesquisador)

Outra dificuldade enfrentada pela adoção do trabalho em equipe está relacionada ao processo de liderança das equipes multi e interdisciplinares (Galbraith et al., 1995). $\mathrm{O}$ esforço analítico empreendido neste trabalho demonstra que a mentalidade técnica e autoritária expressa nos elementos culturais construídos ao longo da existência da organização inibiram a emergência de líderes científicos.

“(...) ainda prevalece uma forma de administração autoritária. Aqui, se você discorda ou critica quem ocupa cargo acaba sendo isolado. O aparecimento de novas lideranças é visto como ameaça ao poder de quem está no comando(...) Se o ambiente não favorece o aparecimento de lideranças, os líderes de projetos acabam sendo indicados e aí é um desastre(...)” (Relato de Entrevista - pesquisador)

A liderança de equipe na organização investigada tem sido sinônimo de aumento de responsabilidade e de trabalho. Para os pesquisadores, a organização criou a figura do líder, mas não definiu uma política de valorização dessas lideranças. Essa falta de valorização e de gratificação pelo exercício da liderança é percebida pelos pesquisadores como algo que dificulta o trabalho multi e interdisciplinar, pois nenhum pesquisador tem interesse em liderar as equipes de trabalho e assumir sua gestão.

(...) o líder nesse processo de mudança é o mais sacrificado. Sob a sua responsabilidade ficou a elaboração de relatórios, a negociação de parcerias e negociação dos conflitos. A empresa fez algumas promessas (viagens e autonomia para decidir sobre a aplicação dos recursos) que nunca cumpriu(...) Assim, sobrou para o líder somente trabalho e responsabilidade(...) E aí, ninguém quer liderar o projeto e a chefia acaba indicando aqueles que ela julga ter competência para isso. Muitas vezes este líder não é bem aceito pelos outros e aí nascem as dificuldades do trabalho em equipe." (Relato de Entrevistapesquisador)

O esforço analítico realizado nesse trabalho possibilita inferir que a institucionalização da cooperação entre os pesquisadores e o alcance da coesão em torno da lógica da pesquisa multi e interdisciplinar é um processo marcado por movimentos de adesão e resistências reforçados por dimensões distintas.

A ausência de raciocínio sistêmico, resultante de um processo de socialização científica que valoriza a lógica reducionista de investigação, faz com que muitos 
pesquisadores apresentem uma tendência a abordar os problemas segundo uma orientação fragmentada. Esse fator acaba levando o pesquisador a concentrar e valorizar esforços teóricos e metodológicos na sua área de interesse e formação. Essa postura origina a construção social de uma espécie de monopólio do saber que lhe confere o poder do expert (Larson, 1990; Crompton, 1990, 1992). Aqui parece emergir um desequilíbrio entre a formação analítica do pesquisador, que enfatiza a especialização e o reducionismo, e a exigência da equipe de trabalho, que pressupõe a construção social de uma visão holística e integrada das cadeias produtivas e dos sistemas de produção a elas associados.

As divergências de orientações, em que a existência de uma diversidade cultural na organização, decorrente da especialização e originada do instrumental teórico de cada disciplina ou área de conhecimento, e a ausência de uma base filosófica e gerencial que sirva de referencial comum à prática da pesquisa multi e interdisciplinar, também parecem desencadear uma série de resistências ao processo de mudança da pesquisa individual monodisciplinar para uma concepção de um trabalho de natureza coletiva.

Os problemas de comunicação, que abarcam a falta de diálogo científico entre pesquisadores de diferentes áreas do conhecimento, da mesma forma, oferecem resistência ao processo de mudança em curso. A comunicação entre os pares encontra algumas restrições que dificultam o alcance de um consenso quanto às posturas teóricas e metodológicas a serem empregadas na concretização das propostas de pesquisa. Os pesquisadores, em função da especialização, tendem a usar uma linguagem e jargões científicos próprios do seu campo de trabalho, dificultando o diálogo $\mathrm{e}$, conseqüentemente, $\mathrm{o}$ trabalho em equipe.

A obsolescência do conhecimento teórico e metodológico de muitos pesquisadores (Brei, 1998b), por sua vez, dificulta sua capacidade de corresponder às demandas do novo modelo de organização do trabalho, pois, por sua natureza, os estudos multi e interdisciplinares apresentam uma maior complexidade e exigem uma maior dedicação e constante atualização. Nesse caso, parece que a emergência de novas ondas tecnológicas, principalmente em áreas estratégicas, como a biotecnologia e tecnologia de informação, vem colocando em xeque o estoque de conhecimento de muitos pesquisadores da organização em estudo.

Finalmente, o individualismo constitui um dos grandes desafios ao trabalho de equipe nessa organização. A tendência individualista de muitos pesquisadores que estão mais preocupados com o reconhecimento social, prestígio e crescimento na carreira desafia a regulação da cooperação e da competição predatória entre os membros da equipe. A cultura parece vivenciar o paradoxo das organizações ditas modernas. Em outros termos, de um lado o modelo de gestão estimula a cooperação, mas do outro premia e promove as ações individuais (Lipnack e Stamps, 1997). Essa ambivalência tem provocado algumas resistências ao trabalho em equipe introduzido a partir da implementação do novo sistema de gestão do planejamento. Associado ao individualismo, há ainda as dificuldades relativas à apropriação dos resultados. Nesse processo emergem ações oportunísticas no momento de dividir as responsabilidades e os resultados do trabalho em equipe.

\section{Considerações Finais}

Esta pesquisa teve por objetivo investigar o processo de adoção do trabalho em equipes multi e interdisciplinares em uma empresa pública de pesquisa e 
desenvolvimento. A perspectiva de análise adotada partiu do pressuposto de que tanto a organização quanto o seu ambiente técnico e institucional são fenômenos socialmente construídos e, portanto, produtos e produtores da consciência humana. Por esse motivo, a análise do novo processo de organização do trabalho implementado, sob a perspectiva dos pesquisadores e gestores da organização, tornou a experiência vivenciada e representada por seus diferentes atores uma instância privilegiada de investigação, ampliando, assim, as possibilidades de compreensão dos processos de mudanças em outras organizações públicas de $\mathrm{P} \& \mathrm{D}$, especialmente em relação ao trabalho em equipe multi e interdisciplinar.

Além disso, a reconstrução histórica dos processos de gestão vivenciados pela organização desde seu surgimento favoreceu o acesso à subjetividade e à intersubjetividade socialmente construídas em torno dos processos de mudança pelos quais passou, permitindo um alcance analítico que vai além das pesquisas que consideram apenas os aspectos objetivos da realidade organizacional. Ademais, mediante o esforço dessa investigação, reconstruiu-se o processo de introdução do trabalho em equipes multi e interdisciplinares, baseando-se na interpretação das representações sociais elaboradas por diferentes atores organizacionais a partir da implementação de um novo modelo de gestão de P\&D. Considerando os limites da revisão de literatura, pode-se afirmar que esta orientação teórico-metodológica não tem sido muito adotada pelos trabalhos científicos que tratam do processo de mudança em organizações de P\&D.

Pelo esforço analítico do presente artigo ficou evidenciado, na organização estudada, a formação de uma cultura organizacional dominante que incorporara alguns traços culturais como, a perpetuação da visão reducionista e produtivista da ciência e da tecnologia, que valorizava a dominação da natureza; a construção social de um mito da competência técnica superior amplamente compartilhada pelos pesquisadores; a construção social de uma forma de dominação racional-legal de natureza autoritária e centralizadora; ações marcadas por um forte espírito de corpo que reforçou a baixa interação com o usuários dos resultados das atividades de P\&D e a institucionalização do individualismo e da monodisciplinaridade.

Ao questionar o seu modelo de organização e gestão da produção científica e tecnológica, diante das mudanças que vêm ocorrendo no ambiente técnico $\mathrm{e}$ institucional das organizações públicas de $\mathrm{P} \& \mathrm{D}$, desde meados da década de 1980, a organização estudada deu início a um processo de mudança organizacional, que incluía a introdução de uma nova organização do trabalho de $\mathrm{P} \& \mathrm{D}$. O desenvolvimento desse processo disseminou um novo conjunto de valores e crenças sobre o futuro da organização, entre eles, a multi e a interdisciplinaridade como fundamentos para a pesquisa coletiva ou em equipe.

A dinâmica cultural produzida em decorrência da introdução da mudança organizacional investigada desencadeou a construção de diferentes representações sociais em torno da organização do trabalho em equipes multi e interdisciplinares. A interpretação dessas construções simbólicas, tomando como referência a cultura dominante institucionalizada ao longo da história da organização, ilustra que a implementação de um novo modelo de organização do trabalho não é um processo que ocorre de forma total, apenas pela modificação na forma de organização da produção científica. Mas, ao contrário, trata-se de um processo que envolve o questionamento e a superação dos padrões culturais até então vigentes nesse espaço organizacional. 
A superação desses padrões culturais e a institucionalização de novos valores organizacionais requerem um reordenamento do universo simbólico que, dependendo das estratégias de regulação e gestão da própria mudança, podem estimular o desenvolvimento de comportamentos de adesão e resistência, de convergência e de divergência. Além disso, os processos de mudança passam necessariamente por um rearranjo das relações de poder e pela aprendizagem dos novos pressupostos orientadores da ação organizacional em direção à conquista da sua legitimidade social.

As reflexões contidas no presente estudo reforçam a tese sobre as dificuldades das transformações culturais nas organizações que geralmente desenvolvem interações sociais, as quais estruturam um movimento que tende mais para a permanência do que para a mudança cultural. Reconhecer a tendência de permanência da cultura não significa, portanto, negar a sua dinâmica, mas, trata-se de reconhecer as dificuldades associadas aos processos de desinstitucionalização dos padrões culturais vigentes na organização e de institucionalização de um novo ethos organizacional que pressupõe a internalização de novos valores.

A descrição e interpretação da dinâmica cultural socialmente construída nessa organização, a partir da implementação de uma nova forma de organização do trabalho de $P \& D$, sugere que o processo de mudança organizacional deve ser visto também como uma arena política e simbólica em que os diferentes atores organizacionais lutam na reorganização dos seus posicionamentos e na elaboração de novas representações que, dependendo dos padrões culturais vigentes na organização, assumem diferentes conotações. Portanto, a mudança organizacional deve ser compreendida como um processo contínuo de reorganização das representações sociais construídas em torno dos processos de gestão implementados, as quais são, simultaneamente, condição e produto das práticas organizacionais.

Nenhum processo de mudança, ao defrontar-se com a cultura organizacional, impõe valores de forma absoluta ou totalitária, ou seja, por mais legítimo que o poder disciplinar seja, haverá sempre possibilidades e espaço para a emergência de conflitos, interpretações divergentes das interpretações dominantes e, principalmente, sempre existirá margem para a emergência de comportamentos de resistências à institucionalização de novos padrões culturais. Assim, como revelado pelas análises presentes nesse trabalho, o universo simbólico socialmente construído ao longo da história dessa organização atuou mais como uma fonte de resistência do que de aceitação das mudanças propostas pela introdução do trabalho em equipe multi e interdisciplinar.

As conclusões reunidas neste artigo poderão contribuir para ampliar o debate sobre a problemática relacionada aos processos de adoção do trabalho em equipes multi e interdisciplinares nas organizações públicas de P\&D. A compreensão da dinâmica cultural socialmente construída, incluindo as suas contradições e as representações sociais elaboradas pelos diferentes atores organizacionais em torno do processo organização do trabalho estudado, pode também propiciar o embasamento necessário à elaboração de projetos de intervenção que conceba outras organizações similares e seu ambiente como produtos socialmente construídos. Logo, portadores de uma dimensão simbólica que deve ser reconhecida e considerada nas propostas de superação dos modelos de gestão em organizações públicas de $\mathrm{P} \& \mathrm{D}$ voltados para o agronegócio, cujos padrões culturais são produto de uma trajetória histórica semelhante. 


\section{Bibliografia}

BARBIERI, T. de. Sobre la categoría género; una introduccíon teóricometodológica. In: AZEREDO, S. ; STOLCKE, V. (coords.). Direitos reprodutivos. São Paulo: FCC/DPE, 1991.

BECKHAM, R. Self-directed work teams: the wave of the future? Hospital

Materiel Management Quarterly. Rockville, aug, 1998.

BERGER, P.; LUCKMAN, T. A construção da realidade social. Petrópolis: Vozes, 1996. 247p.

BEUS, C. E.; DUNLAP, R. E. Conventional versus alternative agriculture: the paradgmatics roots of the debate. Rural Sociology, New York, v.55, n.4, p. 1590616, 1990.

BIRNBAUM, P. Academic Interdisciplinary research: characteristics of successful projects. Journal of the Society or Research Administrators, Washington, v.32, n.3, p.5-15, 1981.

BREI, Z. A. Obsolescência técnica de pesquisadores: um marco conceitual de referência para futuros estudos. Revista de Administração Pública, Rio de Janeiro, v.32, n.3, p.179-193, mai./jun. 1998a.

BREI, Z. A. Obsolescência técnica em organizações de pesquisa e desenvolvimento. Revista de Administração Pública, Rio de Janeiro, v.32, n.6, p.209-224, nov./dez. 1998b.

BRITO, M. J. Mudança e cultura organizacional: a construção social de um novo modelo de gestão de $\mathrm{P} \& \mathrm{D}$ na Embrapa. São Paulo: FEA/USP, 2000. $261 \mathrm{p}$.

CHAMON, E. M. Q. O. A representação social da pesquisa e da atividade do pesquisador. São Paulo. XXI Simpósio de Gestão da Inovação Tecnológica, nov., 2000 .

CHAO, G.T. The socialization process: building newcomer commitment. In: LONDON, M.; MONE, E. Career growth and human resource strategies. Wesport: Quorum, 1988. p.31-47.

CHATMAN, J. A. Matching people and organizations: selection and socialization in public accounting firms. Administrative Science Quarterly, Ithaca, n.36, p.459$484,1991$.

COVALESKI, M. A.; DIRSMITH, M. A.; HEJAN, J. B; SAMUEL, S. Administrative Science Quarterly. Ithaca; Jun 1998 (43).

CROMPTON, R. Patterns of consciousness amongst the middle class. In: BURROWS, R.; MARSH, C. Consumption and class: divisions and change. London: Macmillan, 1992. p.144-165. 
CROMPTON, R. Professions in the current context. Work, employment and society, London, n.3, v.2, p.147-166, 1990.

DEMO, P. Introdução à metodologia da ciência. São Paulo: Atlas, 1985.

DIMAGGIO, P.J.; POWELL, W.W. The iron cage revisited: institutional isomorphism and collective rationality in organizational fields. American Sociological Review, New York, v.48, n.2, p.147-169, 1983.

DOISE, W. et al. Représentations sociales et analyse de données. Grenoble: Press Universitaires de Grenoble, 1992.

FLEURY, M.T.L. $O$ simbólico nas relações de trabalho: um estudo sobre as relações de trabalho na empresa estatal. São Paulo: USP/FEA, 1986. (Tese de Livre Docência).

GALBRAITH, J.R. et al. Organizando para competir no futuro: estratégia para gerenciar o futuro das organizações. São Paulo: Makron Books, 1995. 287p.

GIL, A.C. Como elaborar projetos de pesquisa. São Paulo: Atlas, 1996.

GUIMARÃES, T.A. Organizações e comunidades de pesquisa em biotecnologia agropecuária: os casos do BBSRC (Grã-Bretanha) e da EMBRAPA (Brasil). São Paulo: Faculdade de Filosofia, Letras e Ciências Humanas/USP, 1994, 262p. (Tese de Doutorado em Ciências Sociais).

JODELET, D. Représentations sociales: un domaine en expansion. In: D. Jodelet (Ed.). Les représentations sociales. Paris: Presses Universitaires de France, 1989. 31-61.

JOVCHELOVITCH, S. Vivendo a vida com os outros: intersubjetividade, espaço público e representações sociais. In: GUARESCHI, P.A.; JOVCHELOVITCH, S. Textos em representações sociais. Petrópolis, Vozes, 1995.

KENDALL, S.; MACKINTOSCSH, E.E. Problèmes de gestion des projets de recherche polydisciplinaire sur' enviroment en milieu universitaire. Paris: Man \& Biosphere, 1979. 260p.

LARSON, M.S. In the matter of experts and professionals. In: BRURRAGE, M.; TOSTENDAHL, R. Formation of the profession. London: Sage Publications, 1990. p24-50.

LAVILLE.C. ; DIONE, J. A construção do saber. Belo Horizonte: UFMG, 1999.

LEENDERS, M.R.; ERSKINE, J.A. Case research: the case writing process. Ontario: University of Western Ontario, 1989. 
LICHTENSTEIN, R. et al. Embedded intergroup relations in interdisciplinary teams: effects on perceptions of level of team integration. The Journal of Applied Behavioral Science. Arlington, dec., 1997.

LIPNACK, J; STAMPS, J. Virtual teams: reaching across space, time, and organizations with technology. New York, John Wiley \& Sons, 1997. 262p.

MACHADO-DA-SILVA, C. L.; FONSECA, V. S.; FERNANDES, B. H. R. Um modelo e quatro ilustrações: em análise a mudança nas organizações. In: ENCONTRO ANUAL DA ASSOCIAÇÃO NACIONAL DOS PROGRAMAS DE PÓS-GRADUAÇÃO EM ADMINISTRAÇÃO, 23., 1999, Foz do Iguaçu, PR. Anais eletrônicos... Foz do Iguaçu: ANPAD, 1999. 15p. (Organizações/estratégia)

MACHADO-DA-SILVA, C. L.; FONSECA, V.S. Estruturação da estrutura organizacional: o caso de uma empresa familiar. Organizações $e$ Sociedade, Salvador, v.1, n.1, p.42-71, 1993.

MACULAN, A.; ZOUAIN, D.M. Mudanças na gestão das instituições de P\&D: a experiência do INT. In: ENCONTRO ANUAL DA ASSOCIAÇÃO NACIONAL DOS PROGRAMAS DE PÓS-GRADUAÇÃO EM ADMINISTRAÇÃO, 21., 1997, Angra dos Reis, RJ. Anais eletrônicos... Angra dos Reis: ANPAD, 1997. 15p. (Administração de ciência e tecnologia)

MARTINS FILHO, E.O. Ciência e tecnologia: a natureza de suas relações com a inovação tecnológica e a globalização. Revista de Administração Pública, Rio de Janeiro, v.34, n.4, p.22-37, jul./ago., 1996.

MEYER, J.W.; ROWAN, B. Institutionalized organizations: formal structure as myth an ceremony. In: MEYER, J.W.; SCOTT, R.W. (eds.) Organizational environments: ritual and rationality. London: Sage Publications, 1992. 310p.

MINAYO, M.C. de S. O conceito de representações sociais dentro da sociologia clássica. In: GUARESCHI, P.A.; JOVCHELOVITCH, S. Textos em representações sociais. Petrópolis, Vozes, 1995.

MORGAN, G. Imagens da organização. São Paulo: Atlas, 1996. 422p.

ORLANDI, E. P. Discurso e leitura. São Paulo: Cortez e Unicamp, 1996.

PETERSON, L.W.; ALBRECHT, T.L. Where gender/power/politics collide: deconstructing organizational maternity leave policy. Journal of Management Inquiry, Thousand Oaks: jun, 1999.

RIBEIRO, M.T. A redefinição das agendas dos centros de P\&D: os limites do mercado na sinalização das áreas estratégicas. In: ENCONTRO ANUAL DA ASSOCIAÇÃO NACIONAL DOS PROGRAMAS DE PÓS-GRADUAÇÃO EM 
ADMINISTRAÇÃO, 23., 1999, Foz do Iguaçu, PR. Anais eletrônicos... Foz do Iguaçu: ANPAD, 1999. 15p. (Administração de Ciência e Tecnologia)

; FAUCHER, P.H. O novo papel dos laboratórios públicos no contexto da reestruturação do Estado e dos mercados - o caso IRQ (Québec) e CEPEL (Brasil). Revista de Administração Pública, Rio de Janeiro, v.28, n.3, p.229-249, mai./jun. 1994.

RODRIGUES, S.B. Cultura corporativa e identidade: desinstitucionalização em empresa de telecomunicação brasileira. Revista de Administração Contemporânea, Rio de Janeiro, v.1, n.2, p.45-72, mai./ago. 1997.

SCHEIN, E. Coming to a new awareness of organizational culture. Sloan Management Review, Cambridge, v.3, n.10, p.3-15, 1984.

1992. 240p.

Organizational culture and leadership. San Francisco: Jossey-Bass,

Organizational socialization and profession of management. Sloan Management Review, Cambridge, v.32, n.3, p.53-65, 1988.

SCOTT, W.R. The arganization of environments: network, cultural and historical elements. In: MEYER, J.W.; SCOTT, W.R. (eds.) Organizational environment: ritual and rationality. London: Sage Publications, 1992. 310p.

SITYA, C. V. M. A lingüística textual e a análise do discurso: uma abordagem interdisciplinar. Frederico Westphalen/RS: Ed. da URI, 1995.

SOUZA, I.S.F. de; ARAÚJO, J.D.; CAMPOS, F. Competitividade agrícola brasileira. Administração de Empresas, São Paulo, v.26, n.3, p.33-44, mai.jun. 1991.

SPINK, M.J. Desvendando as teorias implícitas: uma metodologia de análise das representações sociais. In: GUARESCHI, P. A. JOVCHELOVITCH, S. Textos em representações sociais. Petrópolis, Vozes, 1995.

TREVOR, F. PINCH; BIJKER, W.E. The social construction of facts and artifacts: or how the sociology of science and the sociology technology might benefit each other. In: BIJKER, W.E.; HUGHES, P.T.; TREVOR, F. PINCH. The social construction of technological systems: new directions in the sociology and history of technology. London: MIT Press, 1993. 405p.

TRIVINOS, A.N. Introdução à pesquisa em ciências sociais: a pesquisa qualitativa em educação. São Paulo: Atlas, 1992. 176p.

VARGAS, M.R. O poder nas organizações: um estudo das configurações de poder em uma instituição de pesquisa. Brasília, Universidade de Brasília, 1997a. 129p. (Dissertação - Mestrado em Psicologia Social) 
VERGARA, S. C. Projetos e relatórios de pesquisa em administração. São Paulo: Atlas, 1998.

WEBER, M. Ensaios de sociologia. Rio de Janeiro: Zahar, 1982. 530p.

Economia e sociedade: esboço de sociologia compreensiva. Cidade do México: Fundo de Cultura Econômica, 1984. 229p.

YIN, R.K. Case study research: design and methods. Bervely Hills: Sage Publications, 1989. 